\title{
VIDEOGAMES, IMERSÃO E EXPERIÊNCIA SENSÍVEL: UM PARALELO DAS REVERBERAÇÕES NA EDUCAÇÃO TECNOLÓGICA
}

\author{
Video Games, Immersion, and Sensible Experience: A Parallel of Reverberations on \\ Technological Education
}

Caio Túlio Olímpio Pereira da Costa ${ }^{1}$

Ana Beatriz Gomes Pimenta de Carvalho

\begin{abstract}
Resumo: O artigo discute a experiência de jogar e a imersão em narrativas de universos primorosamente simulados (MURRAY, 2003) dos videogames como força-motriz da alteridade no mundo do jogo e na vida cotidiana a partir de processos de aprendizagem. Elencando conceitos como experiência deweyana, comunicação sensível de Marcondes Filho (2010) e reverberações do uso de tecnologias educacionais como processos formativos, formulações de juízos e mobilizações afetivas nos jogadores, o artigo traz uma discussão teórica sobre afetos, usos, percepções e relações humano-maquínicas na Educação e Comunicação enquanto campos multidisciplinares. Emprega, nesse sentido, um percurso metodológico marcado por proposta de discussão teórica a partir de levantamento bibliográfico e observação participante (TRAUTH; O'CONNOR, 1991), que resulta em considerações marcadas pela evidência de que o uso das tecnologias é capaz de mudar o modo como nos vemos, possibilitando novas formas de experimentar o mundo, garantindo um cenário de aprendizado pela multidimensionalidade do conceito atual de letramento.
\end{abstract}

Palavras-chave: Games Studies. Imersão. Experiência sensível. Educação tecnológica.

\begin{abstract}
This research article discusses the experience of playing and the immersion in exquisitely simulated universes' narratives (MURRAY, 2003) as driving force of the alterity in the game world and daily life generated by learning processes. It carries out concepts as Dewey's experience, the sensible communication of Marcondes Filho (2010), and reverberations of the use of educational technologies on formative processes, as well as on ideas and thoughts, and on affective mobilizations reflected on the player. The article also aims at presenting a theoretical dialogue concerning affects, uses, perceptions, and machine-human relationships on Education and Communication as multidisciplinary fields. In
\end{abstract}

\footnotetext{
${ }^{1}$ Doutorando em Educação Tecnológica pela Universidade Federal de Pernambuco, mestre em comunicação pela mesma instituição. Integra o Grupo de Pesquisa Mídias Digitais e Mediações Interculturais (CNPq PPGEdumatec/UFPE) e o Coletivo Interdisciplinar de Pesquisa em Games (CIPEG). É bolsista da Coordenação de Aperfeiçoamento de Pessoal de Nível Superior - CAPEs. Orcid: https://orcid.org/0000-0002-7201-7157. E-mail: caiotuliocosta3@gmail.com.

2 Doutora em Educação pela Universidade Federal da Paraíba. Professora Associada da Universidade Federal de Pernambuco, lotada no Departamento de Métodos e Técnicas de Ensino no Programa de Pós-Graduação em Educação Matemática e Tecnológica (PPGEdumatec). Orcid: http://orcid.org/0000-0002-2572-7383. E-mail: anabeatrizgpc@gmail.com.
} 
addition, it considers a methodological approach of bibliographic review and participant observation (TRAUTH; O'CONNOR, 1991), in which result on considerations highlighted by the evidence of how the use of technology can change the perspective we have from ourselves, developing new possibilities on how to perceive the world, addressing a learning scenario based on the actual multidisciplinary concept of literacy.

Keywords: Games Studies. Immersion. Sensible experience. Technological education.

\section{Introdução}

No tocante ao campo multidisciplinar que agrega a Comunicação e a Educação enquanto ciências, especificamente onde a experiência pragmática através de vivência se desprende um pouco mais do catedrático e passa a abraçar algo de recorrência comum, temos o videogame, que enquanto interface comunicacional facilitadora de fruição de experiência, não apenas a conduz, mas sim a constitui como parte indissociável.

A experiência de jogar um jogo eletrônico, como tecnologia digital da informação e comunicação, é genuína e recorrente nesses campos, visto que "tudo ao nosso redor produz sinais que podem ou não ser convertidos em componentes do processo comunicacional" (MARCONDES FILHO, 2010, p. 15). Entretanto, sob essa ótica, é preciso que quem recebe esses sinais queira, de fato, recebê-los. O sensível e a razão presente nas narrativas experimentadas pelo jogador, nesse contexto, se aproximam da arte explorada por Dewey (2010) como forma de apreensão sensível do mundo em que vivemos, que para Marcondes Filho (2010 apud JÁCOME, 2014, p. 55) "ocorre igualmente nas formas sociais maiores de contato com objetos, especialmente com objetos culturais das produções televisivas, cinematográficas, teatrais, nos espetáculos de dança, nas performances, nas instalações", assim como em ambientes de relacionamento virtual. Nessa perspectiva, podemos perceber alguns diálogos entre Ciro Marcondes Filho (2010) e John Dewey (2010), principalmente no que diz respeito ao caráter estético da experiência através do videogame, que bebendo das fontes da Comunicação e da Educação é marcado pela apreensão sensível do mundo conectivista que vivemos. Dessa relação percebe-se um campo sensível que se manifesta a partir de cada estruturação de sentidos que perpassa o decifrar de linguagens, plataformas e seus esclarecimentos. Nesses ambientes não estão presentes apenas informações, mais além, está formulada uma dimensão de afetos, que consequentemente geram blocos de sensações (DUARTE, 2014, p. 55).

Para acessar esse conteúdo de forma satisfatória é necessário dispor de um letramento digital ou até mesmo ludoletramento. Este, é baseado a partir de uma diversidade de linguagens e de mídias e de uma diversidade cultural, onde através dos jogos digitais um aprendizado de competências cognitivas por meio do lúdico pode emergir (ROJO, 2013). Contudo, estes blocos mencionados previamente detêm força que atravessa e perpassa todos que se deixam tomar por esse encontrão sensível (DELEUZE; GUATTARI, 1997), que é mobilizado por afetos. Tomamos essa perspectiva teoria também a partir de uma multidimensionalidade do conceito atual de letramento. Partindo do pressuposto de que o mundo é palco das experiências de deslocamento, é relevante mencionar que não precisamos estar de corpo presente em muitos ambientes para termos experiências genuínas, até mesmo no campo sensível, o que traz a ideia do transporte imersivo para realidades primorosamente simuladas no videogame (MURRAY, 2003). Temos as narrativas que emergem nesse aparato, muitas vezes, como ambientes passíveis de apreensão sensível, que dispensam o deslocamento físico em detrimento de um palco de experiências que é formado na conexão 
das relações humano-maquínicas. Essas relações, por sua vez, se formulam como uma disposição do ensino-aprendizagem. Contudo, "as práticas educativas, sejam elas escolares ou não, constituem o ponto de articulação entre a formação de uma sociedade ou de uma humanidade e a formação dos sujeitos que compõem e são formados por essa coletividade" (SILVA et al., 2018, p. 5).

Entendemos esse quadro como resultado de uma fricção, que detém a viabilidade de fazer o indivíduo pensar em possibilidades narrativas e/ou sensoriais que não havia experimentado antes. Para Marcondes Filho (2010), esse quadro gera uma comunicação densa capaz de trazer o novo à tona, pois possibilita parâmetros para analisar um processo comunicativo gerado dessa relação. Esse, por outro lado, faz emergir modificações às formas de pensar, sentir e interpretar o mundo a nossa volta (MARCONDES FILHO, 2010). No caso do videogame, baseado em suas narrativas, suas formas de transporte e projeção-identificação do jogador com elementos narrativos, enxergamos um quadro possível desse caso, concebendo uma reconfiguração de pensamento, onde é possível resgatar inclusive do campo das memórias (BERGSON, 1999) algo que até o presente momento não tínhamos noção que estava em nosso cerne. "Essa descoberta de algo que não se sabia antes é o expor-se à 'violência', é o ato de a comunicação nos fazer pensar nas coisas, nos outros, em nós mesmos, na nossa vida" (MARCONDES FILHO, 2010, p. 22). Esses parâmetros, no presente contexto, configuram a experiência sensível, pois é através dela mesma e sua partilha que uma redescoberta do mundo contemporâneo pode emergir a partir do vivenciado por uma narrativa digital.

$\mathrm{O}$ videogame é dotado por mediar e proporcionar experiências sensíveis aos jogadores através da imersão. O transporte causado pela relação humano-maquínica nesse ponto nos leva a pressupor que os impactos e demais efeitos trocados e partilhados pelo jogo-jogador (ambiente-indivíduo) possibilita um leque de contornos individuais infinitos, variando e se moldando de forma diferente para cada experimentação dos universos fantásticos oferecido por essa interface comunicacional. Após essa partilha e retroalimentação onde o indivíduo transforma o jogo digital por sua vivência e o jogo digital transforma o indivíduo por sua narrativa, o videogame torna-se capaz de estreitar relações entre os espaços reais e virtuais, originando e resgatando configurações que podem impactar os processos sociais de mobilizações afetivas (JÁCOME, 2014) através de uma perspectiva de aprendizado por experimentação que reverbera em questões de letramento. O letramento, nesse contexto, se constitui como uma constelação de práticas que orbitam vivências que não são necessariamente de nosso cotidiano regular. Podemos habitar textos, performar e produzir pela aprendizagem, legitimar conhecimentos pela capacidade de funcionar no mundo e participar ativamente através de produção e consumo (LACERDA; SCHLEMMER, 2018).

Por vezes utilizamos o termo "relação humano-maquínica" quando abordamos as formas de transporte do real para o virtual no presente artigo. Entretanto, no contexto da comunicabilidade sensível, faz-se necessário informar que a vivência nesses mundos virtuais, muitas vezes chamada de ilusão ou puramente determinação maquínica, na verdade detém uma relação e experiência que vai muito além da de operador-aparelho. Nos referimos aqui a uma convivência com a alteridade no mundo do jogo, que em sua raiz produz elementos que são desencadeados também pela subjetividade do indivíduo. A modernidade, por sua vez, assimilou experiência à subjetividade. Baseado nesses propostos, o presente artigo busca compreender através de perspectiva teórica recortes de mobilizações afetivas e formulações de juízo a partir do uso do videogame em contextos educacionais. 
Para atingir esse objetivo, foi proposta uma discussão teórica a partir de levantamento bibliográfico e observação participante (TRAUTH; O'CONNOR, 1991), enquanto método de investigação qualitativa, a fim de enriquecer o material explorado através de um relacionamento multilateral. Espera-se desse instrumental analítico uma consistência singular de apuração, registrando uma expressividade sobre a temática. Nesse sentido, a metodologia tem intento de construir possibilidades teórico-metodológicas que proporcionem leitura qualitativa de pontos intrínsecos ao uso do videogame na Educação, que parte da avaliação crítica dos próprios autores com as obras e títulos de videogame assim como a percepção sobre esses jogos digitais na academia.

\section{Da retroalimentação entre jogo e jogador em contextos educacionais}

Gomes (2008), sobre a construção dos personagens autônomos nos videogames, afirma que a narratividade dos jogos não brota de forma pura e simples de uma intenção pré-determinada. Esta, pelo contrário, emerge da experiência do jogar, e detém agenciamento que facilita a imersão e criação de sentido no próprio jogador. Além do mais, partimos do pressuposto de que a narrativa que exploramos nos jogos de videogame não se configuram exclusivamente como uma cadeia de causa-e-efeito que pode ser atravessada, acionada e experimentada a partir da cognição ou pela corporização digital do jogador, por exemplo. Nos referimos, nesse ponto, a um processo de modelização de universos conceituais em que o jogador habita da maneira que assim desejar, fazendo com que cada experiência seja única e individual nesse processo (GOMES, 2008). A grosso modo, a imersão em narrativas digitais dos videogames não funciona como uma receita de bolo. Contudo, todos esses transportes imersivos por cada jogador são dotados de trazer experimentações incomuns da vida cotidiana, que podem formular sentidos, ideias e juízos que sirvam de aprendizado para o usuário na vida offline.

O avatar (GOMES, 2003) age como uma representação corpórea no mundo do jogo, que obedecendo aos comandos do jogador se configura como extensão do movimento físico no âmbito digital, para que assim a narrativa seja vivenciada. Nesse âmbito, a narrativa, por si só, é uma forma muito antiga de organização da experiência. Para além de uma sistematização de toda uma tradição oral, é pensada como uma "forma fluida, comunal, que emergiu nas sociedades orais a partir da necessidade vital de, pela linguagem verbal oral, dar sentido à experiência do vivido (GOMES, 2008, p. 42). Consequentemente, nesse raciocínio, temos essa mesma tradição narrativa oral se desenvolvendo a partir da necessidade de "sistematizar a experiência em forma de conhecimento" (ibidem). E o videogame, nesse campo, é um artefato que permite a ressignificação da atualização dessa tradição para o contexto cibercultural.

Conferir sentido, primordialmente, estaria atrelado mais uma vez às formas de pensar, sentir e interpretar o que nos rodeia. Para isso, a apreensão pela intuição sensível permite, através da experiência individual, "a obtenção de um conhecimento adquirido de uma só vez e sem conceitos" (MARCONDES FILHO, 2014, p. 112), o que gera, consequentemente, uma pureza na partilha do sensível. Inclusive, apenas mediante essa postura temos como perceber o real sentido e propriedades do ato comunicacional, captando então sua essência e natureza.

Respaldados por Dewey (2010), podemos afirmar que a experiência é automática, é orgânica, como se as ações que desencadeiam memória fossem o juízo de uma subjetividade que nos molda e reflete para o externo. Porém, consideramos que a subjetividade é construída da objetividade (DUARTE, 2015). Essa objetividade, por sua vez, também dialoga com o apontamento de que o sujeito da experiência: 


\begin{abstract}
Se define não por sua atividade, mas por sua passividade, por sua receptividade, por sua disponibilidade, por sua abertura. Trata-se, porém, de uma passividade anterior à oposição entre o ativo e o passivo, de uma passividade feita de paixão, padecimento, de paciência, de atenção, como uma receptividade primeira, como uma disponibilidade fundamental, como uma abertura essencial (BONDÍA, 2002, p. 24).
\end{abstract}

A abertura para o desconhecido é o que o jogador se submete quando experimenta as realidades primorosamente simuladas apresentadas pelo videogame. E, ainda, se o repertório de vivência de alguma forma dialogar com o que está sendo formulado na retroalimentação do indivíduo-ambiente, através da superfície da ação que gera reações imediatas em interação com o mundo (DUARTE, 2015), é possível afirmar que há vazão para uma congruência entre os territórios do pensamento e dos fenômenos práticos. A interação, nesse sentido, se formula como um intercâmbio entre condições subjetivas, localizadas no cerne do ser humano, em conjunto das condições objetivas. Entretanto, estas nomenclaturas atuam somente como conceituações da análise da experiência. Não há distinção, para Dewey (2010), do que está dentro ou fora, pois, como apenas uma instância, tudo faz parte da experiência humana.

A experiência, consequentemente, inclui "o que os homens fazem e sofrem, o que eles se esforçam por conseguir, amam, creem e suportam, e também como os homens agem e sofrem a ação, as maneiras pelas quais eles realizam e padecem, desejam e desfrutam, veem e creem, imaginam" (DEWEY, 1958, p. 8). Logo, é plausível dizer mais uma vez que a experiência se constitui, primordialmente, como a própria vida do homem.

"Desta forma, podemos afirmar que tudo está na experiência humana e se está desconectado da ação, não é experiência no sentido deweyano do conceito porque não há intenção ou reflexão, nem aprendizagem" (MARCONDES, 2017, p. 39). Também, a título de contextualização, toda experiência está viva, autêntica, se perpetuando nas próximas que virão. As experiências passadas, portanto, estão diretamente ligadas à ideia de inteligência. Afinal, é possível afirmar que as experiências agem como conhecimento, que é utilizado, nessa instância, para "projetar novas ações por meio da construção de hipóteses, pois a experimentação envolve o próprio processo de experimentar: passado e futuro compõem o fluxo da experiência" (MARCONDES, 2017, p. 49). Trata-se de um aperfeiçoamento das ações (BERGSON, 1999).

Exemplificando esses propostos substancializados em um jogo eletrônico, trago o caso que um dos pesquisadores autores vivenciou, através da observação participante, com o título Dark Souls, de 2012. Desenvolvido pela empresa From Software, trata-se de um RPG (Role-Playing Game) de ação, onde o jogador aprende a jogar pela dor. Tornou-se, na época de seu lançamento, um recrudescer da dificuldade, com regras, jogabilidade e mecânicas difíceis e exigentes (ALEXANDRE, 2017). Definitivamente, Dark Souls não é um jogo convidativo para os que não detém um letramento no gênero videogame. Em outras palavras, para os que não detém o hábito de jogar. Essa afirmação se faz presente no artigo pelo fato do jogo específico não dispor de um tutorial inicial para guiar o jogador, ou não ter um nível de dificuldade que cresce gradualmente ao longo da narrativa (sendo sempre programado para "ser difícil" a todos os momentos). O novo jogador, considerando ser Dark Souls sua primeira experiência com videogames, se depararia com muitas frustrações até se acostumar com as mecânicas, afinal, até para os mais experientes o título se mostra frustrante em certos momentos. Já estas mesmas mecânicas bebem da fonte de gêneros de jogos de aventura, RPG e ação. Em sua narrativa linear, erros são severamente punidos, fazendo com que o jogador 
repita demasiadamente passos e momentos até memorizar e aprender padrões que possam, enfim, garantir o sucesso. Estes, bem recompensados digitalmente.

Pereira (2016) atesta que o fracasso é o ponto central do jogo, e a repetição é a verdadeira atração. A experiência de deixar o personagem que controlamos morrer, inúmeras vezes, e com isso voltar todo o trajeto já jogado é no mínimo cansativo. Porém, para muitos jogadores isso pode ser um estímulo. Por outro lado, o ponto principal de trazer essa exemplificação é a que de caso nos concentremos, estejamos dispostos a aprender, a memorizar e a experimentar as inúmeras mortes dentro do jogo, o sucesso e o progresso na narrativa acabam por vir. Nesse âmbito, a partir dos fracassos e derrotas, sabemos onde o dragão vermelho dará uma investida na próxima vez, ou que tipo de golpe será dado quando escutamos um tipo específico de grunhido inimigo. Sabemos, inclusive, a distância ideal para que possamos aparar um golpe certeiro. Porém, só é possível assimilar esse conhecimento após nos condicionarmos às mortes e fracassos prévios. $\mathrm{O}$ fator sorte, obviamente, conta nesse processo de jogo. Entretanto, por ser estruturado em códigos que realmente estão ali para dificultar o progresso do jogador, Dark Souls convida o usuário para vencer a partir das experiências fracassadas, que após aprendizado, memória e interações indivíduo-ambiente, conseguirá compreender esse universo e suas sensibilidades. Afinal, a fé na experiência, para Dewey (2010), não produz algo como uma devoção. Entretanto, garante um esforço pelo progresso. Nesse sentido, a própria experiência é que é responsável por conduzir seu aperfeiçoamento. E, também, somos capazes de aprender com as experiências pelo fato de observarmos resultados da ação que não estavam claros antes, ou que até mesmo não tínhamos como observar.

A perspectiva do aprendizado tangencial pela própria experiência do jogar também é percebida fora do contexto percebido em jogos comerciais ou tidos como educacionais. Isolando a presença (ou falta de presença) de narrativa, tomamos em cena os simuladores de voos ou de direção. A questão que elencamos nesse produto não diz respeito ao que deve ser considerado jogo ou não, se é lúdico ou não, ou até mesmo se produz narrativa ou se o indivíduo/usuário que atribui sua própria narrativa (retroalimentação) ao contexto simulado. Gomes (2003) atesta que a Força Aérea Brasileira, tendo software homologado pela Agência Nacional de Aviação Civil, produziu simuladores de voo da aeronave C-105 Amazonas, trazendo os holofotes para a manutenção da integridade física de pilotos e substituindo horas de treinamento com redução de custos. Nesse caso específico, temos os mesmos dispositivos digitais simulando com verossimilhança o real, onda a retroalimentação pela experiência deweyana é o que pode garantir ao piloto uma licença de profissão. Levando esse mesmo contexto para a situação do ambiente escolar formal, unir e se apoiar nos jogos digitais não quer dizer transformar o local de aprendizado em uma lanhouse, e sim tangenciar o ensino-aprendizagem a partir de atividades relacionadas aos jogos digitais, considerando experiência, imersão e uma exploração crítica das potencialidades educativas (PIMENTEL, 2018).

Consequentemente, através do sensível, ainda nos referenciando a subjetividade, toda essa relação faz surgir o conjunto das condições que torna possível que instâncias individuais e/ou coletivas estejam em posição de emergir como território existencial auto-referencial (GUATTARI, 1992). Pois, nesse campo, o videogame enquanto máquina originada da tecnologia, é capaz de formular experiências, significados, emoções e sensações que atuam diretamente na produção da subjetividade humana, em um jogo de efeitos colaterais que configuram o circuito da experiência, culminando no aprendizado. 


\section{A Experiência sensível no videogame}

Para que se evidencie o sensível nas transformações acarretadas pela comunicação do jogo-jogador, em fim de compartilhamento, é preciso considerar uma alteridade com a experiência do outro, aqui interpretada também como a forma de lidar com o diferente. Nesse sentido, a mensagem, como registro simbólico que retrata a experiência ativa, passa por deformações e ressignificações quando é interpretada pelo outro, pois, muitas vezes, esse indivíduo não detém repertório ou não compartilha as mesmas experiências para que seja possível deduzir e compreender o lugar do autor e sua mensagem pela forma como se expressa. Por isso, na comunicação, a partir dos propostos de Ciro Marcondes Filho (2010), uma mensagem jamais chega de forma fidedigna no outro, pois, não funciona como uma inserção mecânica ou uma espécie de download de sistema para sistema.

Nesse contexto, a comunicação não comunica, entretanto, performa. E essa característica de performance é responsável por moldar a mensagem até que seja possível criar sentido para ela. Nesse caminho, obviamente, se criam ruídos que dificultam a apreensão. Diante de tantos dispositivos tecnológicos capazes de comunicar, assim como letramentos específicos para operar esses dispositivos, nossa maior preocupação, na contemporaneidade, é saber como essas máquinas, em especial o videogame, no caso do presente artigo, nos toca. E, consequentemente, como compartilhamos nossas experiências desse toque. Atravessando tudo isso, emerge um ponto crucial dessas relações, o afeto. Onde através da compreensão do outro, uma alteridade, torna-se possível afetivamente ser tocado. Nessa instância, laços de afetividade e laços de confiança podem se configurar na recepção da mensagem, na compreensão da experiência do outro e seu aprendizado.

Enxergamos o videogame nesse contexto como dotado de mobilizar potências sociais, onde após reter experiências, os jogadores possam misturá-las, em diálogo. Nesse âmbito, as subjetividades também se mesclam a medida em que os relatos de imersão emergem e a comunicação performa. Essa prática, inclusive, é dotada de agenciar comportamentos distintos, tanto nos âmbitos individuais ou coletivos, online e offline, no videogame ou longe dele. Esse espaço de diálogo apresenta uma diluição das subjetividades, pois, colocar-se à disposição do jogo garante um momento que dá um disparo de ampliação de subjetividade, oriundo de uma dimensão e herança antropológica.

O jogo, portanto, performa a comunicação. Entretanto, a experiência sensível cria um repertório de base de experiência. E na comunicação, que por muito tempo foi vista através do modelo clássico (fundamentalista, inclusive) entre emissor e receptor através do meio, pensava-se em um modelo metafórico sistematizado que bebia da fonte da ideia de caixas de processamento cognitivos (input/output). Entretanto, no final da segunda metade do século XX, o pensamento metodológico da comunicação foi observando que essa demonstração funcionalista poderia servir como metáfora, em quadro geral, para demonstrar o que realmente se passa na comunicação.

Porém, não descrevia de fato o que ocorre quando a comunicação leva em consideração as pessoas que usam dessas informações e mensagens. Porque, em verdade, realmente, na transmissão de informação e de conhecimento, o receptor nunca recebe a mensagem plenamente pelo emissor por não se tratar, conforme mencionado anteriormente, de um download. No download existe uma quantidade de "quilobytes" de informação que é transmitida de um aparelho para outro. Porém, esse receptor garante após a transação exatamente o mesmo pacote de informações enviado pelo emissor. Nossa humanidade, por outro lado, nos garante que não pensamos como máquinas como nessa metáfora, afinal, somos seres humanos. Nesse âmbito, nem o emissor consegue plasmar em linguagem tudo 
aquilo que deseja comunicar, e nem o receptor consegue absorver tudo aquilo para então decodificar. Seres humanos interpretam, deformam e performam a mensagem que criam e a mensagem que recebem. Como não somos máquinas, o processo de elaboração de mensagem, por si só, já é uma deformação. E o processo de recepção, nesse contexto, já se configura como outra deformação.

Afirmamos essas questões a partir dos apontamentos de Marcondes Filho (2010), pois tudo o que temos a dizer é indizível dentro da transformação de uma linguagem. Entretanto, conseguimos pactuar uma série de entendimentos suficientes a respeito do que temos a dizer. Mas uma grande quantidade de coisas que gostaríamos de expressar nos escapa, primordialmente por não sabermos como formular.

O videogame, enquanto máquina, não escapa dessa situação, afinal, é idealizado por humanos (desenvolvedores de jogos) que detém as mesmas configurações de comunicação de seu jogador. Às vezes, algo presente na narrativa de um jogo reverbera porque há um pouco do vivido em algum lugar do outro. Entretanto, isso não pode ser feito por completo porque cada ser humano é resultado de uma vida de experiências, baseada na forma como cada um foi moldado nas ideias, nos valores, na educação. Esses campos são primordiais para podermos interpretar e construir em nós mesmos a estrutura emocional dessas sensações. Porém, passar toda informação é impossível, pois a real intenção é intransferível. Nessa perspectiva, blocos de sensações dão conta, na verdade, de uma dimensão inominável na nossa própria cultura. Os sentimentos já são, por outro lado, nomeações, partes significantes, visíveis, que possuem significados na nossa cultura. Estes operam na construção da mensagem, e são utilizados para que se possa elaborar algo a se dizer para seu receptor. Apesar de todas essas considerações, faz-se necessário firmar mais uma vez que a comunicação performa ao invés de informar. Pois, o efeito informativo da comunicação diz respeito a tudo que pode ser informado objetivamente, pragmaticamente, no contexto cultural, que todos podemos interpretar da mesma forma. Já o performativo diz respeito a tudo que mexe, que revira, que provoca rejeição, adesão, prazeres estranhos, elementos que são indizíveis.

A ideia de experiência geral, portanto, nos foi constituída de uma forma em que as instâncias subjetivas e as instâncias pragmáticas são atravessadas pela própria experiência. No campo dos videogames, outra vez, podemos afirmar que nenhum jogador joga o mesmo jogo eletrônico, mesmo que aquele conjunto de hardware ou software seja, de fato, o mesmo título. Isso ocorre porque a quantidade de sensações que são performadas no jogo ocorre de modo diferente para cada indivíduo, independente das regras, mecânicas e afins. Gadamer (1997) confere a possibilidade de estabelecermos, enquanto jogamos, uma habitação do universo proposto. Dessa relação, portanto, construímos uma intimidade vivencial. Além disso, através do que o jogo performa em nós, podemos nos indagar do que o aparato tecnológico realmente dispara no jogador. $\mathrm{Na}$ experiência sensível, o universo do jogo acontece no efeito performático de atravessá-lo. E dessa relação surge, portanto, um campo próprio em que as sensações vão dando significações afetivas, em um processo formativo. O software, nesse contexto, apenas aciona o território por onde a emoção para a educação performa.

\section{Considerações finais}

A partir dos propostos das seções anteriores, podemos inferir que a utilização dos videogames enquanto objeto educacional em contextos de ensino-aprendizagem através da experiência pode ser uma declaração de certo modo vanguardista. Entretanto, fazem emergir questões que necessitam de espaço na discussão acadêmica sobre tecnologias, interações 
humano-maquínicas e aprendizado. Para alguns educadores mais conservadores esse tipo de união entre o videogame e a educação pode parecer ousado, e apenas nos campos teóricos, como no caso do presente artigo, pode parecer pouco viável em sua proposta. Contudo,

[...] o conceito de educação (ex ducere) como ação que leva a ampliação dos sujeitos envolvidos no ensinar e aprender, justaposto a um conceito de jogo como lugar de ampliação das práticas existenciais dentro de um sistema organizado por regras, evidenciam que ambos, educação e jogo, partem de um mesmo princípio fundamental: a integração entre sujeitos e suas novas experiências cognitivas a partir da emulação de uma ambiência virtual (MASTROBERTI, 2019, p. 1027).

A integração e a interação, a partir da experiência de jogar e imersão narrativa e tecnológica, se mostra como elemento-chave que propicia novas possibilidades de aplicação dos videogames na educação em seu sentido mais amplo, abrangendo campos como práticas pedagógicas, ensino, docência e até mesmo currículo (COSTA, 2020).

Porém, explorar conclusões sobre o dinamismo do videogame enquanto interface comunicacional e aparato educacional é no mínimo algo que necessita de muita cautela. Por nos referirmos a um artefato que tende a produzir efeitos imediatos e é passível de acarretar reverberações na vida futura do indivíduo que com ele interage, corremos o risco de apontar certezas prematuras, que em pouquíssimo tempo podem ser palco de novos questionamentos e indagações a respeito de sua efetividade. Entretanto, por ser um requerimento exigido pela prática científica formal, nos atentaremos em apontar nossas considerações sobre o universo de conexões entre jogo eletrônico e jogador. Contudo, nesse sentido, faz-se necessário advertir também que uma parcela das conclusões, mais do que auxiliar no processo de bater uma estaca de ponto final na pesquisa, nos oferece a percepção de inúmeros percursos que se fazem viáveis diante dos desejos de investigar distintas questões que o presente artigo se propôs possibilitar.

Ainda, pelo percurso percorrido, tivemos a chance de compreender como mobilizações afetivas experimentadas na vivência dos jogos e seus mundos simulados ocorrem, principalmente quando elencada a observação participante do dualismo que habita entre o pesquisador/jogador e o corpus. Nesse espectro, consideramos também uma recorrência das memórias afetivas do passado afetando o futuro. Momentos que marcam a vida de alguns dos jogadores, seja pela sociabilidade que o jogo eletrônico enquanto palco fomentou no passado, ou até mesmo por características intrínsecas aos títulos que puderam ressignificar traços da personalidade, mobilizações afetivas podem ser registradas. Nesse sentido, inferimos que jogos eletrônicos podem mudar estilos de vida, a forma de ver o mundo, como se enxerga, inclusive, os próprios jogos. Dessas perspectivas emergem considerações marcadas pela evidência de que o uso das tecnologias é capaz de mudar como podemos nos ver, possibilitando novas formas de experimentar o mundo, garantindo um cenário de aprendizado. Consequentemente, dessa relação, são aguçados desejos de expressão e sensibilidade, que quando em partilha podem garantir uma epifania desses sentidos. Portanto, as manifestações das mobilizações afetivas recuperam e valorizam as dinâmicas do sensível. Pelos propostos, foi possível através dessa mesma perspectiva verificar como a experiência de imersão no videogame é capaz de formular ideias e juízos que podem ser refletidos no cotidiano do usuário mesmo longe do aparato tecnológico. Tratamos, portanto, de um letramento inserido na cultura digital, bebendo de fontes da cultura da convergência, em perspectiva conectivista, que deve se apoiar em aprendizagem tangencial até portarmos 
"estudos empíricos que nos forneçam consistência" sobre a aurora de um letramento gamer (PIMENTEL, 2018, p. 15).

Essa estratégia, que se baseou no esforço individual pensado para o coletivo para que os blocos de sensações se fizessem compreensíveis, se apropria ao máximo da performance comunicativa, permitindo uma aproximação/intimidade conferida pelo compartilhamento de vivências. Através de uma experiência crua e rica com os títulos apresentados ao longo do artigo, assumindo as personas de pesquisador e jogador, concebemos que histórias de vida diversas, situações e percursos formativos em que o videogame tem lugar privilegiado como estopim de um turbilhão de sentimentos podem emergir como saldo do vivido (COSTA, 2020). O videogame, ainda, serviu como palco fantástico para que percebamos seu potencial sobre o imaginário. A relação entre esse imaginário e a experiência sensível, por outro lado, também facilitou a concepção do videogame como uma tecnologia da imagem e do imaginário, que detém forte efeito no contexto de aprendizagem por experiência. A fruição dessa tecnologia educacional, a partir da interatividade de jogo-jogador (ambiente-indivíduo) age como disparador cognitivo de sensibilidades e sensações, e até mesmo emoções, que podem revelar uma mínima parcela de efeitos e práticas que constituem um oceano de possibilidades que podemos imergir.

\section{Referências}

ALEXANDRE, V. TOP 10: Os jogos mais difíceis de sempre. Eurogamer Portugal, 2017. Disponível em:

$<$ https://www.eurogamer.pt/articles/2017-10-11-top-10-os-jogos-maisdificeis-de-sempre?page $=4>$. Acesso em: 28 jan. 2020 .

BERGSON, H. Matéria e Memória: Ensaio sobre a relação do corpo com o espírito. São Paulo: Martins Fontes, 1999.

BONDÍA, J. L. Notas sobre a experiência e o saber da experiência. Revista Brasileira de Educação, n. 19, 2002. Disponível em: <https://www.scielo.br/pdf/rbedu/n19/n19a02.pdf >. Acesso em: 30 jan. 2020.

COSTA, C. A experiência sensível na imersão em jogos de videogame. Dissertação (Mestrado em Comunicação), 175f, 2020. Programa de Pós-Graduação em Comunicação, Centro de Artes e Comunicação, Universidade Federal de Pernambuco, 2020.

DELEUZE, G.; GUATTARI, F. O que é a filosofia? 2. ed. Rio de Janeiro: Editora 34, 1997.

DEWEY, J. A arte como experiência. Trad. Vera Ribeiro. São Paulo: Martins Fontes, 2010.

DEWEY, J. Experience and nature. New York: Dover Publications, 1958.

DUARTE, E. Um estatuto científico para a experiência sensível. In: PICADO, Benjamim; MENDONÇA, Carlos Magno Camargo; CARDOSO FILHO, Jorge (org.). Experiência

Estética e Performance. Salvador: EDUFBA, 2014. 
DUARTE, E. Para além de toda forma de ciência, a experiência sensível. Revista Líbero, v. 18, n. 35. São Paulo, 2015. Disponível em:

$<$ http://seer.casperlibero.edu.br/index.php/libero/article/view/69>. Acesso em: 20 jan. 2020.

GADAMER, H. Verdade e Método I: traços fundamentais de uma Hermenêutica Filosófica. Rio de Janeiro: Vozes, 1997.

GOMES, Renata. Agentes verossímeis: uma investigação sobre a construção dos personagens autônomos nos videogames. 2003. Dissertação (Mestrado em Comunicação e Semiótica) - Pontifícia Universidade Católica de São Paulo - PUC-SP, 2003.

GOMES, Renata. Imersão e participação: mecanismos narrativos nos jogos eletrônicos. 2008. Tese (Doutorado em Comunicação e Semiótica) - Pontifícia Universidade Católica de São Paulo - PUC-SP, 2008.

GUATTARI, F. Da produção da subjetividade. In: GUATTARI, F. Caosmose: um novo paradigma estético. Rio de Janeiro: 34, 1992.

JÁCOME, M. L. Comunicação, experiência sensível e cidadania: a construção do comum entre comunidades virtuais e espaço urbano. Dissertação (Mestrado em Comunicação), 2014. Programa de Pós-Graduação em Comunicação, Centro de Artes e Comunicação, Universidade Federal de Pernambuco, 2014.

LACERDA, M.; SCHLEMMER, E. Letramento digital e práticas educativas gamificadas: uma experiência nos anos finais do Ensino Fundamental. SBC: Proceedings of SBGames 2018, Education Track - Full Papers. SBGames 2018, Curitiba, 2018.

MARCONDES FILHO. C. O princípio da razão durante: O conceito de comunicação e a epistemologia metapórica: nova teoria da comunicação III. Tomo V. São Paulo: Paulus, 2010.

MARCONDES FILHO, C. Das coisas que nos fazem pensar: o debate sobre a Nova Teoria da Comunicação. São Paulo: Ideias \& Letras, 2014.

MARCONDES, O. Dewey: Estética social e educação democrática. 2017. Tese (Doutorado em Educação) - Universidade de São Paulo - USP.

MASTROBERTI, Paula. Ludopoéticas: Relações possíveis entre jogo, arte e educação a partir de ações de pesquisa. In: Anais do SBC - Proceedings of SBGames e XVIII Simpósio Brasileiro de Jogos e Entretenimento Digital, Rio de Janeiro, 2019.

MURRAY, Janet H. Hamlet no Holodeck: o futuro da narrativa no ciberespaço. São Paulo: Itaú Cultural - UNESP, 2003.

PEREIRA, A. Eu morro, tu morres, eles morrem: Heurísticas para uma boa experiência de fracasso nos videojogos. 2016. Dissertação (Mestrado em Ergonomia) - Universidade de Lisboa, 2016. 
PIMENTEL, F. Letramento digital na cultura digital: o que precisamos compreender? Revista Educação a distância e práticas educativas comunicacionais e interculturais, v. 18, n. 1, 2018.

ROJO, Raquel. Multiletramentos, multilinguagens, novas aprendizagens [entrevista]. In: GRIM UFC, Fortaleza, 2013.

SILVA, R. et al. Os serious games e os regimes de sensibilidade: Paradoxos do uso de jogos na formação humana. Arquivos Analíticos de Políticas Educativas, v. 26, n. 117, 2018. Disponível em: <https://lume.ufrgs.br/handle/10183/184804>. Acesso em: 31 jan. 2020.

TRAUTH, E.; O'CONNOR, B. A Study of the interaction between information technology and society. Amsterdam: North-Holland, 1991.

Recebido em janeiro de 2021.

Aprovado em maio de 2021. 